\title{
USGS Releases Landsat Orthorectified State Mosaics
}

The U.S. Geological Survey (USGS) National Remote Sensing Data Archive, located at the USGS Center for Earth Resources Observation and Science (EROS) in Sioux Falls, South Dakota, maintains the Landsat orthorectified data archive. Within the archive are Landsat Enhanced Thematic Mapper Plus (ETM+) data that have been pansharpened and orthorectified by the Earth Satellite Corporation. This imagery has acquisition dates ranging from 1999 to 2001 and was created to provide users with access to quality-screened, high-resolution satellite images with global coverage over the Earth's landmasses.

The Landsat Orthorectified Pansharpened ETM+ scenes for each state are radiometrically matched and merged with the corresponding Digital Elevation Model (DEM) data. Various vector data, such as collar information, state flags, and annotation, are added. A thumbnail image, along with the pertinent ordering information, is put on the EROS Web page, as shown in Figure 1. There are multiple methods for ordering these data. A Joint Photographic Experts Group (JPEG) file is created for customers who want a small digital version at no cost. The full-resolution Tagged Image File Format (TIFF) file can be ordered for a small fee. An example of the ordering screen showing Virginia is depicted in Figure 2.

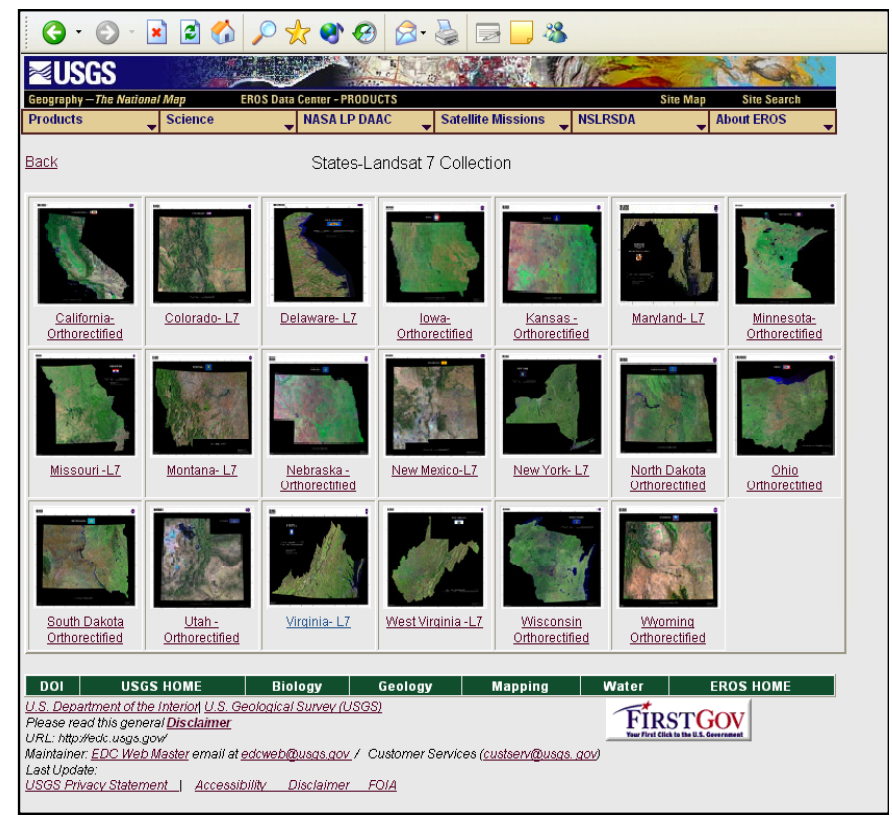

Figure 1. State mosaic Web page

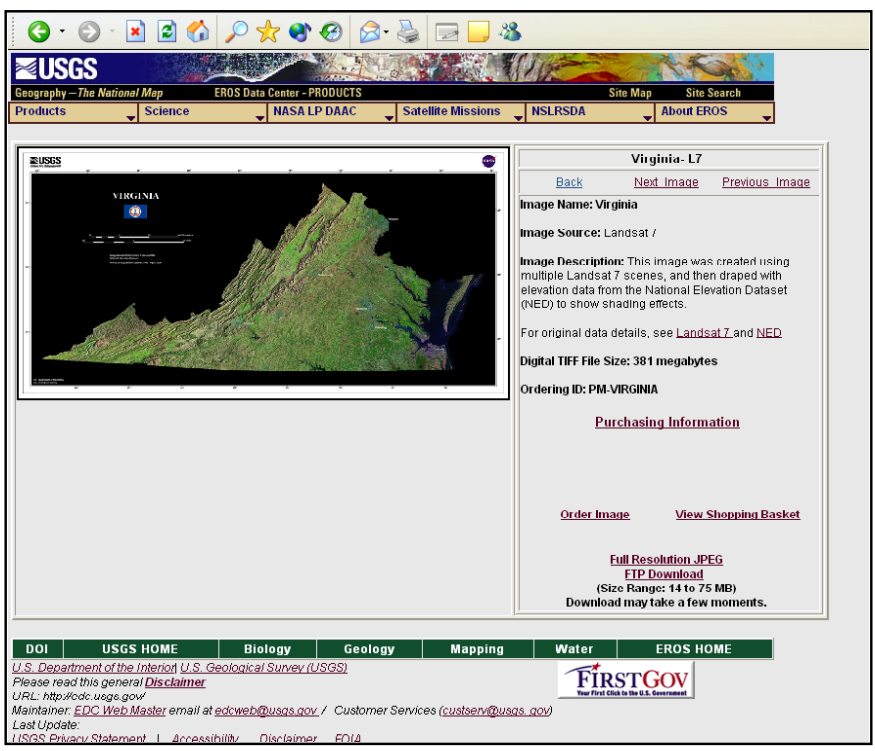

Figure 2. State mosaic ordering page

The current status of the state mosaics is depicted on the back page in Figure 3.

\section{For More Information}

For additional information on state mosaics and ordering procedures, visit http://edc.usgs.gov, then go to Image Gallery and States-Landsat 7, or contact:

U.S. Geological Survey (USGS)

Center for Earth Resources

Observation and Science (EROS)

Customer Services

Mundt Federal Building

Sioux Falls, SD 57198-0001

Phone: 800-252-4547

Phone: 605-594-6151

TDD: 605-594-6933

Fax: $\quad 605-594-6589$

Email: custserv@usgs.gov 


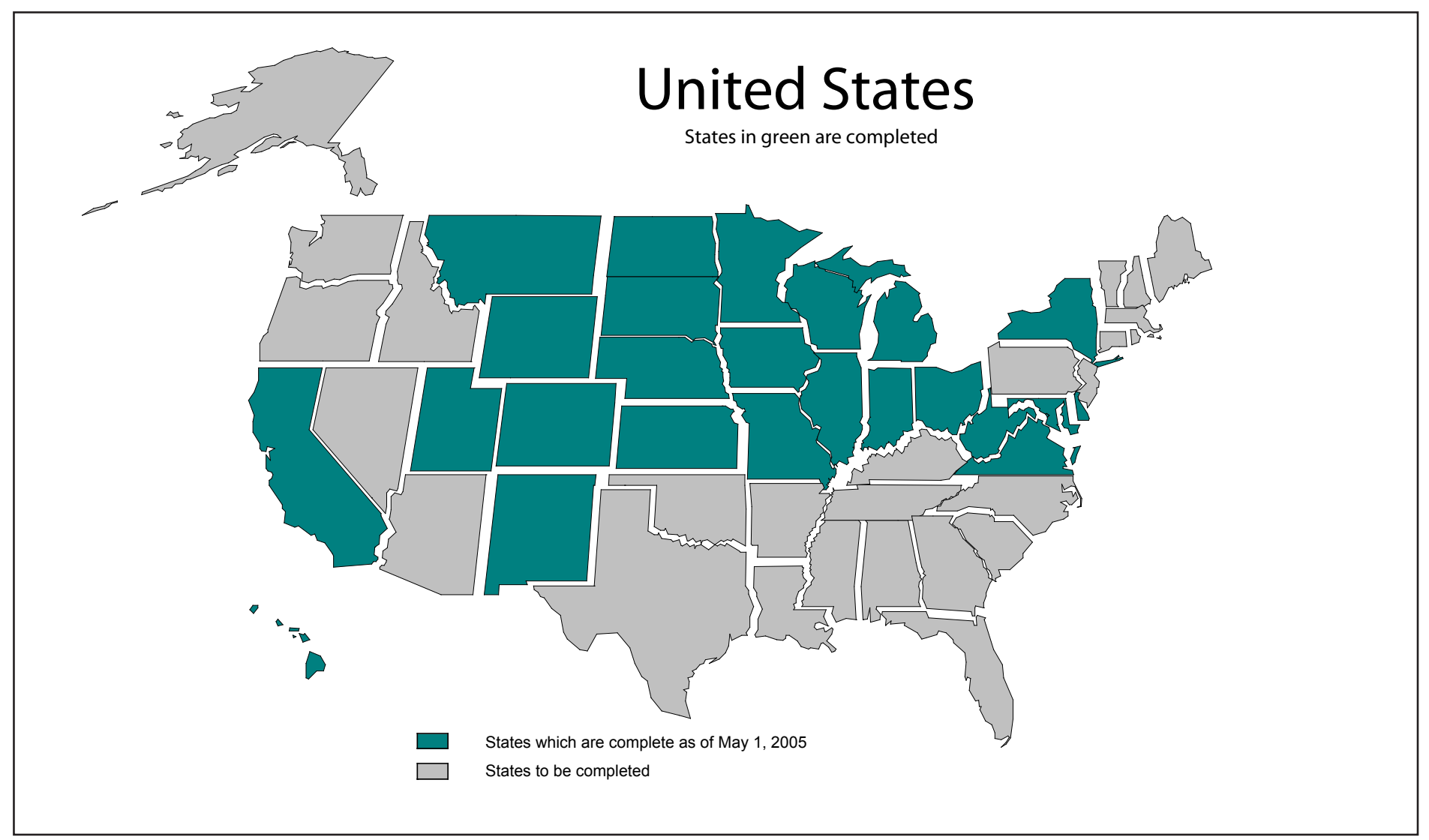

Figure 3. The states shown in green have been completed, while the gray states are yet to be mosaicked.

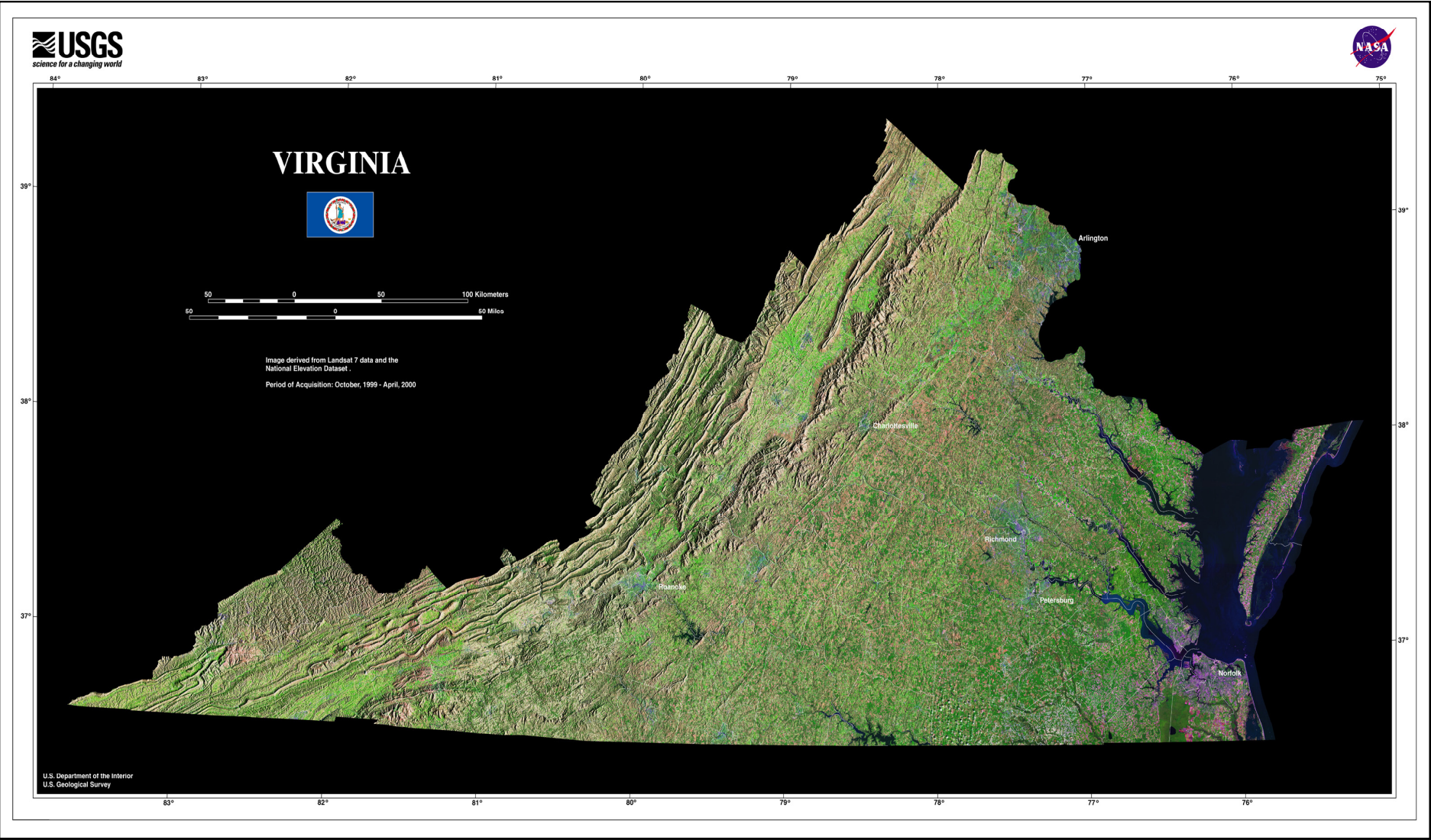

Figure 4. The state of Virginia downloaded as a JPEG file. 